\title{
Neural insights into the relation between language and communication
}

\author{
Roel M. Willems ${ }^{1 *}$ and Rosemary Varley ${ }^{2}$ \\ - Helen Wills Neuroscience Institute, University of California Berkeley, Berkeley, CA, USA \\ 2 Department of Human Communication Sciences, University of Sheffield, Sheffield, UK
}

Edited by:

Ivan Toni, Radboud University,

Netherlands

Reviewed by:

Helen Tager Flusberg, University of

Massachusetts, USA

Ivan Enrici, University of Turin, Italy

*Correspondence:

Roel M. Willems, Helen Wills

Neuroscience Institute, University of

California Berkeley, 210 Barker Hall,

Berkeley, CA, USA.

e-mail: roelwillems@berkeley.edu

\begin{abstract}
The human capacity to communicate has been hypothesized to be causally dependent upon language. Intuitively this seems plausible since most communication relies on language. Moreover, intention recognition abilities (as a necessary prerequisite for communication) and language development seem to co-develop. Here we review evidence from neuroimaging as well as from neuropsychology to evaluate the relationship between communicative and linguistic abilities. Our review indicates that communicative abilities are best considered as neurally distinct from language abilities. This conclusion is based upon evidence showing that humans rely on different cortical systems when designing a communicative message for someone else as compared to when performing core linguistic tasks, as well as upon observations of individuals with severe language loss after extensive lesions to the language system, who are still able to perform tasks involving intention understanding.
\end{abstract}

Keywords: language, communication, intention, neuroscience

\section{INTRODUCTION}

Communication can be viewed as a matter of coding and de-coding linguistic information. The speaker codes information and puts his thoughts into words, while the listener de-codes the linguistic information, taking the input from the speaker and translating it back into a thought. In this scenario, it is the code (in this case language) that matters for communication. Individuals with a common code can communicate because they share that code. This is an intuitively appealing view given that communication in our everyday lives so often relies on language, be it in face-to-face conversation, talking on the phone, writing an e-mail, or other forms of exchange. The position that it is the code that matters for communication is nicely phrased by the philosopher John Searle:

"One can in certain special circumstances 'request' someone to leave the room without employing any conventions, but unless someone has a language one cannot request of someone that he e.g., undertake a research project on the problem of diagnosing and treating mononucleosis in undergraduates in American universities." (Searle, 1969, p. 38)

By this view, we are capable of communicating to some degree without language, but real communication requires language and all essential communication is linguistic. In terms of cognitive architecture, this has led to the proposal that understanding others and communicating with others by necessity involves the language system (e.g., Carruthers, 2002). By contrast, numerous scholars have argued for at least an additional inferential ability which crucially underlies our communicative skills, as we will describe below.

In the context of this special issue (Understanding human intentional communication), we consider how evidence from human neuroscience provides insight into the question of whether the capacity for language and the capacity to communicate are cognitively (and neurally) distinct, or whether they are best understood as a single cognitive capacity.

\section{LANGUAGE AND COMMUNICATION}

It is obvious that literal de-coding of linguistic utterances cannot be an adequate and complete explanation for communicative behavior (it is "commonsensical" in Sperber and Wilson's words; Sperber and Wilson, 1995, p. 23), and is clearly illustrated by two examples:

\section{1) "Do you know what time it is?" \\ 2) "Oh man, a beer would do me good after all this hard work"}

The expected answer to (1) is not just the affirmative "yes" (except in slapstick movies) and (2) may be more adequately interpreted as a request for a drink than as a factual statement about the belief of the speaker with regard to the relationship between beer and emotional wellbeing. In natural communication it is the capacity to infer someone's intention from an utterance which seems more fundamental than the linguistic de-coding of the message. This common-sense statement has been discussed and refined at length in the study of pragmatics ("the study of language usage," Levinson, 1983; see e.g., Sperber and Wilson, 1995; Tirassa, 1999; Levinson, 2006; Tomasello, 2008; Airenti, 2010; Bara, 2010). For the present purpose it is important to highlight the argument that to be able to adequately understand or generate a communicative act, one needs to be able to infer another person's intentions or beliefs.

Although it may seem trivial to claim that language and communication are not the same cognitive construct, there is a potent literature arguing that the cognitive system for language crucially underlies our ability to infer others' intentions. Some argue that the structure of human language is crucial for representing higherorder beliefs, as required for mentalizing (Carruthers, 2002; Pyers, 2006; Newton and de Villiers, 2007). For instance, it is proposed that the human mind can only construct representations in which one proposition is embedded inside of another (e.g., Mary thinks [that the money is in the safe]) through the mediation of language and, 
in particular, the recursive capacity of the grammar. Evidence for this position comes from the finding that language development and performance on false belief tasks, requiring such higher order structures, are strongly correlated (see Milligan et al., 2007 for review). In a false belief task a participant is confronted with a scenario in which one of the characters has an incorrect belief about the state of the world. The dependent variable is whether the participant (often a child) will evaluate the character's behavior based upon the present ("actual") state of the world, or based upon the false belief that the character has. If the participant takes the belief of the character into account, she is said to possess a "theory of mind" about others, or to "mentalize" about others' beliefs, desires, and intentions (Wimmer and Perner, 1983; Baron-Cohen et al., 1985).

A second proposal is that verbs describing speech or cognitivementalizing states such as thinking and remembering are necessary for representing the intentions of others. An intriguing demonstration supporting such a link is the finding that deaf adults learning a sign language only start to perform well on false belief tasks after they master typical "mentalizing" verbs such as "believe" or "think" (Pyers and Senghas, 2009).

In this paper we explore the question of the relationship between language and communication/intention understanding from the perspective of human neuroscience. In particular, we address the question whether there is evidence from neuroimaging and neuropsychological studies to suggest that language and communication are supported by overlapping or distinct parts of the brain.

\section{A NEURAL PERSPECTIVE \\ EVIDENCE FROM PATIENT POPULATIONS}

If inferences regarding someone's beliefs and intentions necessarily require the resources of the language faculty, either from the lexicon (e.g., mentalizing verbs) or the recursive capacity of the grammar in embedding one proposition within another, then individuals with severe language impairment would fail on theory of mind (ToM) tasks. Patients with severe agrammatic aphasia usually display deficits in the comprehension and production of verbs, and these impairments are particularly evident on low imageability, abstract verbs such as those that describe mental states (McCarthy and Warrington, 1985). Severe agrammatism is also characterized by difficulties in de-coding the structure of sentences, with impairment in assigning correct agent-patient roles in reversible sentences such as "the diver splashed the dolphin"/"the dolphin splashed the diver." More complex structures containing subordinate clauses provoke even greater difficulties in comprehension. There are parallel difficulties in creating structured sentences, with output at best consisting of strings of words (usually nouns), and at worst, restricted to social forms such as "hi," "yes," or "bye."

Despite the presence of such profound language impairments, patients with severe aphasia are able to succeed on tests of false belief understanding (Varley and Siegal, 2000; Varley et al., 2001; Apperly et al., 2006). These patients all had extensive damage to left hemisphere perisylvian cortex including the traditional fronto-temporal language network (see Figure 1). That these patients could perform false belief tasks despite their severe damage to the language network and concomitant linguistic difficulties, is a first indication that mentalizing tasks do not necessarily rely upon the language system.

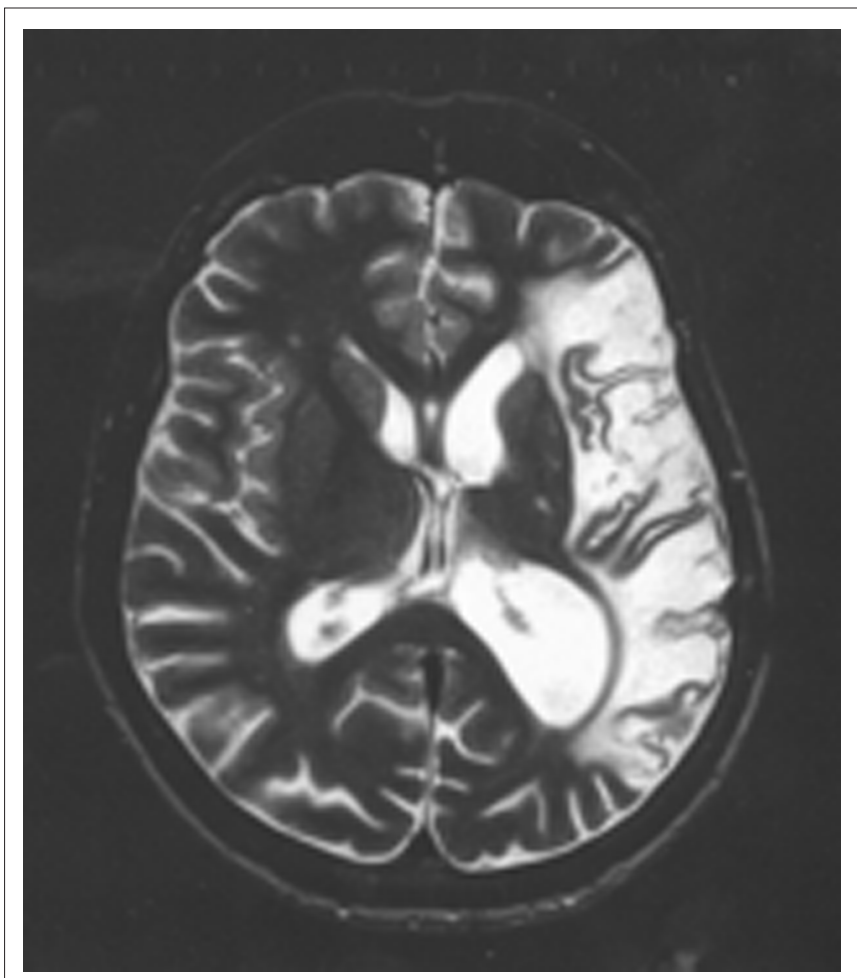

FIGURE 1 |An axial slice of an anatomical scan of one of the patients tested on a false belief task in Varley and Siegal (2000). Note the extensive damage in the left hemisphere, encompassing the whole cortical language network. The images are displayed following radiological convention which means that the left hemisphere is on the right side of the image.

With regard to the inter-relationship between language and communication, patients with severe aphasia have often been observed to communicate better than they talk. Through the use of alternative communicative resources such as drawing, facial expression, and gesture some severely aphasic individuals are able to convey quite sophisticated messages (see Siegal and Varley, 2002 for an example). Goodwin (2006) provides an in-depth analysis of the communicative abilities of a severely aphasic man, with a special focus on conversational aspects. For instance, by using expressive prosodic cues (e.g., emphasis and pitch), the aphasic person was able to communicate messages while only using non-sense syllables (Goodwin, 1995, 2006).

In a recent study, we investigated the capacities for communicative intention generation in several aphasic patients in an experimentally controlled set-up (Willems et al., submitted). Three profoundly aphasic patients engaged in a communicative paradigm called tacit communication game (TCG), which involves two players with different communicative roles. The paradigm consists of a $3 \times 3$ grid on which each player can move around his/her visual token, consisting of a simple shape (Figure 2 ). The overall goal is to move the tokens to a preconfigured end-state. There is an imbalance in knowledge between the two players: one player knows the desired end-state of a trial, whereas the other does not. Hence, one player has to use his own token to convey the desired end-position and orientation of the other player's token. Since the means of communication in this paradigm is novel (moving 
A

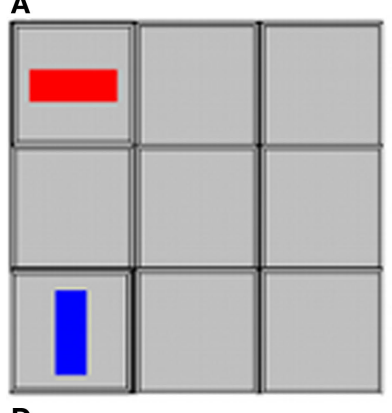

D

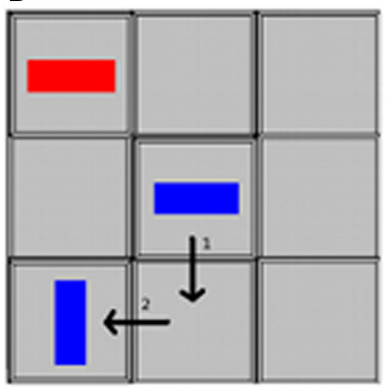

B

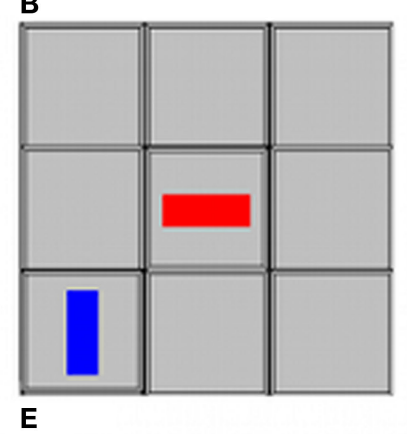

C

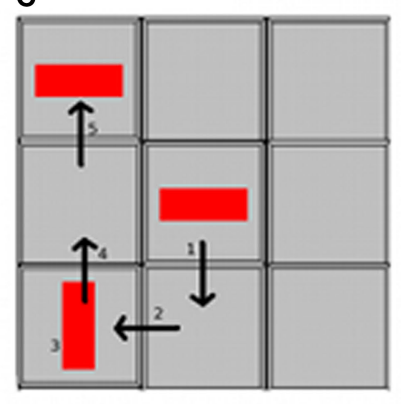

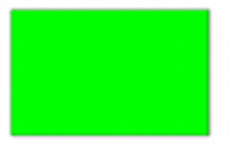

FIGURE 2 |The TCG playing board and tokens and sequence of events in a trial, viewed from the Sender's perspective. The Sender's token is in red, the Receiver's token is in blue. (A) The Sender sees the goal configuration. The Receiver does not see the goal configuration. (B) The
Sender sees the start configuration. (C) The Sender moves his token around and gives the turn to the Receiver. (D) The Receiver moves her token into the position and rotation indicated by the Sender. (E) Both players get feedback (green square). tokens on a playing board), participants have to generate a new communicative strategy in order to convey the relevant information to the other player. Examples of such strategies are to pause longer on the desired end-location of the other player, or to move back and forth between the desired end-location and a neighboring location to indicate the desired orientation (de Ruiter et al., 2007, 2010; Newman-Norlund et al., 2009). The rationale of our patient study was that if language is crucially involved in communicative intention generation, the aphasic patients should not fare well on this task. However, the patients exhibited strategies for communication that were entirely comparable to those observed in the neurologically healthy population. These findings indicate considerable autonomy between language and intentional communicative capacity.

Adopting a different experimental strategy, Bara et al. (2001) showed that patients with non-focal closed head injuries can be unimpaired on standard linguistic test batteries, but exhibit difficulties with pragmatic aspects of language understanding such as understanding deceit. Similarly, Happé et al. (1999) revealed that patients with right hemisphere lesions who were not aphasic, displayed impairment on tasks requiring attribution of mental states to others. Taken together, the capacity to form pragmatic inferences requiring some degree of mentalizing can be preserved in aphasia, but non-aphasic brain-injured patients may display the reverse dissociation, with retention of core linguistic systems of syntax and lexis, but disruption of pragmatic-mentalizing capacity. However, interpretation of data from patients such as those with closed head injury is complex. These individuals may have deficits in cognitive capacities such as inhibiting a potent response and these may impact on performance on arguably high-order types of language tasks such as understanding deceit or irony. Consequently, it remains unclear as to whether an impairment observed in mentalizing represents a primary deficit, or whether it is secondary to disruption of another cognitive process that is necessarily engaged in high-order cognitive processing.

In addition to illuminating the role of language in theory of mind reasoning, these studies indicate the continuing importance of patient-lesion studies in cognitive neuroscience. While functional imaging studies reveal the activations associated with a particular behavioral-cognitive performance, the lesion method represents a means of determining whether the activations reflect a necessary neurocognitive component of the processing network (Bird et al., 2004). If performance is maintained despite "knockout" of a substrate, the findings point either to a non-mandatory processing component or more generally, to plastic, adaptive neural networks underpinning some forms of cognition.

\section{EVIDENCE FROM HUMAN NEUROIMAGING}

Very few neuroimaging studies have looked directly at the relationship between communicative and linguistic abilities. There is a relatively large literature investigating the neural basis of "mentalizing" or ToM (see Amodio and Frith, 2006; Frith and Frith, 2006 for reviews), as well as a sizeable number of studies investigating psycholinguistic factors in language production/comprehension such as semantic, syntactic, and phonological factors (see Bookheimer, 2002; Indefrey and Levelt, 2004; Hagoort, 2005; Vigneau et al., 2006 for review), but only a few studies have looked at communicative and linguistic capacities within the same experiment. 
Sassa et al. (2007) presented healthy young participants with short movie clips of a person handling a familiar object (e.g., someone playing guitar). Participants responded to these movie clips in two different task settings. In one task they talked to the person on the screen in a "casual," communicative manner (Communicative trials), whereas in the other task they were required to describe the scene presented in the movie and not to direct their speech to the person in the movie clips (Descriptive trials). Both conditions involved speech production, but only in the Communicative trials was there an intentionally communicative component to the speech. Comparison of Communicative to Descriptive trials showed increased activation in medial prefrontal cortex (MPFC), left temporo-parietal junction and the temporal poles bilaterally. This set of regions is part of what has been described as the mentalizing network (Amodio and Frith, 2006; Frith and Frith, 2006). Both Descriptive and Communicative trials compared to baseline led to activation in parts of the traditional language production network, such as left inferior frontal gyrus ("Broca's area"; Indefrey and Levelt, 2004), but these regions were not sensitive to the Communicative/Descriptive manipulation.

Willems et al. (2010a) directly tested sensitivity of cortical areas to an increase in communicative intent on the one hand and general linguistic processes on the other hand. Participants were engaged in a communicative paradigm called the "Taboo game." In this set-up the participant's task is to describe a "target word" (e.g., "beard") to another individual without using certain predetermined "Taboo words." That is, there was one person inside an MR scanner generating verbal descriptions of various words, while the other player listened to these descriptions outside of the MR scanner and guessed the target word. There were two experimental manipulations: First, communicative intent was manipulated by changing whether the listener already knew the target word or not. Importantly, the participant was aware of whether the other player knew the target word or not. If the listener already knows the target word, the utterance that the participant is creating is not helpful to the listener. We labeled these trials Non-targeted. By contrast, in Targeted trials, the utterance provided by the participant was generated in order to help the other player guess the target word. Second, the linguistic difficulty of a trial was manipulated. If the Taboo words are closely related to the Target word (e.g., "moustache," "chin," and "man" in the case of the target word "beard"), one needs to search a wider semantic space to come up with a helpful description, which makes the task more semantically difficult as compared to when the Taboo words are more distantly related to the target word. These trials were labeled Difficult and Easy.

The distinct manipulation of Communicative intent and Linguistic difficulty was neatly reflected in activation patterns in different brain regions (Figure 3). A part of MPFC was more strongly activated to Targeted as compared to Non-Targeted trials (the Communicative intent manipulation), but did not show sensitivity to the linguistic difficulty manipulation (Figure 3A). By contrast, left inferior frontal, and left inferior parietal cortex were more strongly activated to Difficult as compared to Easy trials, but were not influenced by the communicative intent manipulation (Figure 3B). In summary, this study provides neural evidence for a dissociation between communicative message generation and lexico-semantic language processes.
Both these studies suggest that producing a communicative act for another person relies on different brain areas than those involved in language. Furthermore, the areas that are activated during communicative message generation are those that have previously been observed to be activated in response to mentalizing tasks.

Besides these direct comparisons of language and communicative processes, there have a been a number of studies investigating intention understanding during communication as such, without necessarily focusing on the relationship with language. As we noted above, the neuroimaging literature on mentalizing is extensive (see Amodio and Frith, 2006; Frith and Frith, 2006 for reviews) and we will focus here only on studies that involve materials specifically tailored to investigating communicative intentions.

Walter et al. (2004) investigated the neural distinction between understanding of private intentions/beliefs and understanding of communicative intentions. In their fMRI study, participants viewed short cartoon stories involving people performing actions driven by private, non-communicative intentions (e.g., changing a broken light bulb because you want to read) as well as stories in which characters act with a clear communicative intent (e.g., pointing to a bottle to request it). Their main finding was increased activation in MPFC for the communicative stories as compared to the individual intentional action stories. Moreover, the latter condition did not activate MPFC more strongly than a control condition of nonintentional, physical interactions (e.g., a leaf being blown away by the wind). This study highlights the importance of a communicative component in driving MPFC activation as opposed to intention recognition per se (see also Ciaramidaro et al., 2007).

Kampe et al. (2003) investigated which areas become more activated when someone is called by his own name ("Hey John!") versus by another person's name. The rationale is that calling someone by his name is a potent indicator of the intention to communicate with this person, whereas shouting another person's name is not. The main result was activation in parts of the mentalizing system (MPFC and temporal poles) when participants heard and saw someone calling their name as opposed to another's name. Adopting a different approach, Tylen et al. (2009) used photographs of objects or signs that had either a communicative intention or no communicative intention. For instance, they compared photographs of an arrow on the ground (communicating direction) or chairs blocking a parking space (signaling "do not park here") versus objects lying on the floor and chairs around a table, not signaling a communicative intent. The results showed increased activation to communicative versus non-communicative objects in a set of language related areas including the inferior frontal gyri, but not in the traditional mentalizing network. These results are not easy to interpret in the context of this review since it is conceivable that looking at the intentional photos leads to greater or more elaborate vocalizing/ language processing than looking at the non-intentional pictures. Another contrasting finding comes from Schippers et al. (2009) who did not observe sensitivity of the MPFC (or other mentalizing network areas) to the intentional observation of communicative gestures as compared to observation of the same gestures with the explicit instruction not to interpret their meaning.

Finally, Noordzij et al. (2009) found right posterior temporal cortex to be specifically involved in the generation as well as understanding of an intentional communicative act. They required 

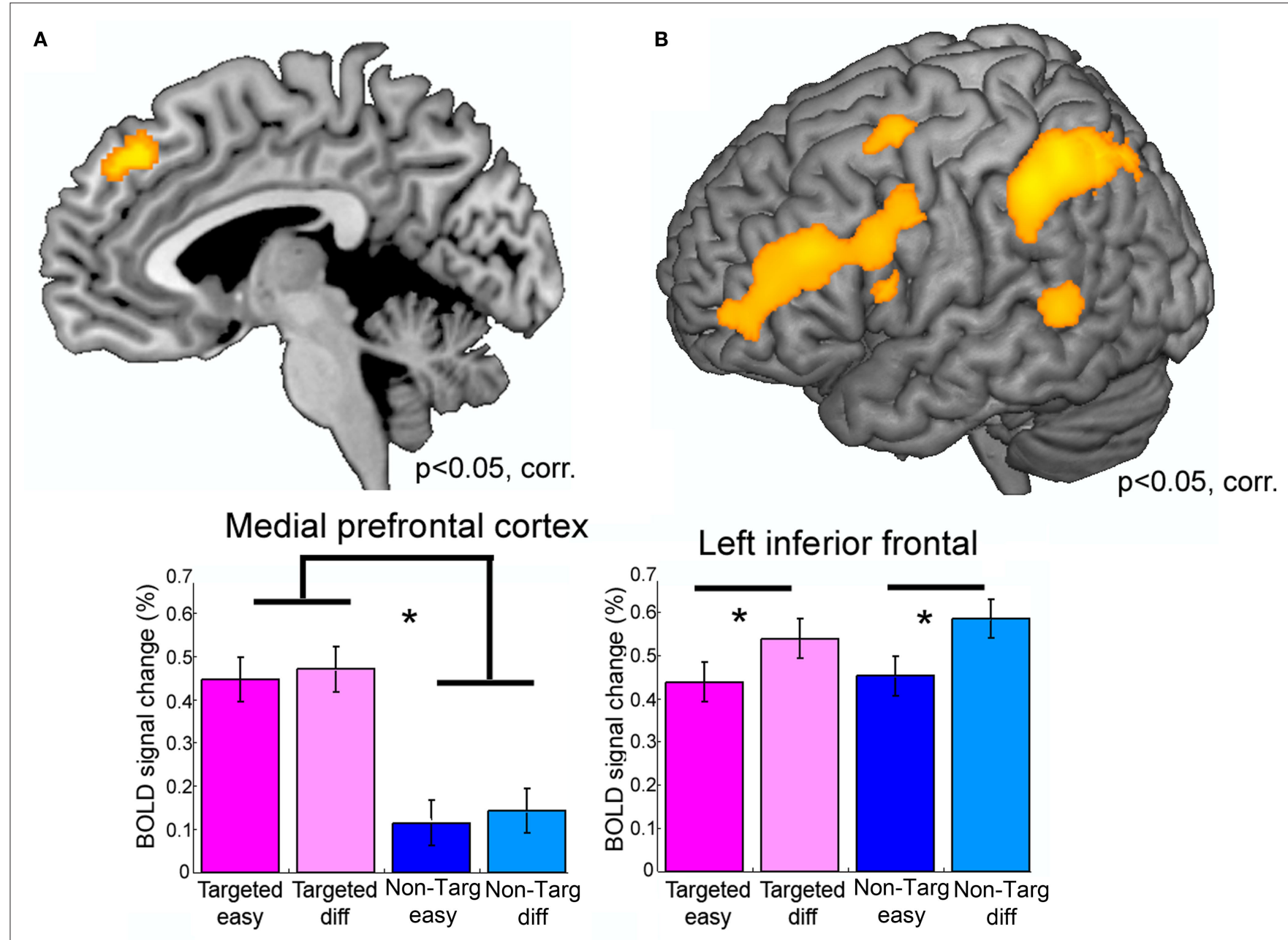

FIGURE 3 | A neural dissociation between communicative and linguistic abilities. Results from an fMRI study in young healthy participants. Participants generated a description of a given concept ("Target word") while they were prohibited to use certain Taboo words. Two factors were manipulated: (1) Communicative intent: The participants created the description either for another individual ("Targeted trials") or not for a specific other individual ("Non-Targeted trials") and (2) Linguistic difficulty: Taboo words were either semantically closely related to the Target word, making it more difficult to come up with a description, or were semantically less closely related to the Target word, which makes it more Easy to come up with a description. (A) Shows the result of comparing Targeted versus Non-Targeted trials, (B) shows results of the Difficult versus Easy comparison. The results show that medial prefrontal cortex was sensitive to the Communicative intent manipulation (A), but not to the linguistic difficulty manipulated, whereas an opposite pattern was observed in left inferior frontal cortex (B). Figure adapted from Willems et al. (2010a). healthy volunteers to engage in the visuo-spatial communication paradigm that we described above (TCG). Participants communicated the position and orientation of a visual token to another individual, using only limited visuo-spatial means. It was observed that activation in right posterior superior temporal cortex/temporo-parietal junction was increased when an individual designed a communicative act for another person, as well as when that second person interpreted the communicative act of the first person. This region has been implicated in mentalizing tasks before, and echoes the findings of mentalizing deficits in right hemisphere damaged patients (Happé et al., 1999 see Amodio and Frith, 2006; Frith and Frith, 2006 for reviews). The overlap is interpreted as evidence for similar mechanisms engaged in generation and interpretation of communicative intentions.

\section{DISCUSSION}

The work that we have reviewed here argues for a neural dissociation between communicative and linguistic capabilities. First, there is evidence from lesion patients who despite severe damage to the language system perform well on mentalizing tasks, as well as on tasks involving the generation of a communicative message for another person. Second, neuroimaging in the neurologically healthy population indicates that distinct parts of the brain are involved in the generation of a communicative message as compared to linguistic processes. Hence, our main conclusion is that communicative abilities should be best understood as neurally - and cognitively - distinct from language and that successful communication does not necessitate, nor rely upon a functioning language system. We take this as strong evidence for the proposal 
that communicative and linguistic abilities are cognitively distinct (Tomasello et al., 2005; Levinson, 2006; Tomasello, 2008; Airenti, 2010; Bara, 2010).

\section{SEPARATE CAPACITIES OR EXTENDED LANGUAGE NETWORK?}

It would be a mistake to interpret our conclusion of separate cognitive capacities for language and communication as meaning that language and communication have little to do with each other. On the contrary, as we described in the introduction, it is trivially the case that language is used mainly and perhaps almost exclusively in a communicative manner in everyday life. Indeed, part of the success story of the human species is due to its capacity to use language as a communicative device.

The fact that our capacity to understand the intentions of others is interlinked with normal language use, has led some to propose an "extended language network," encompassing mentalizing related areas such as MPFC as well as areas more traditionally implicated in language (Ferstl et al., 2008). We are sympathetic to the notion that language entails more than the traditional semantic, syntactic and phonological processing of spoken and written words. Indeed, neuroimaging studies show that "non-linguistic" input such as from hand gestures and from visual information activate parts of the traditional language network (Willems et al., 2007, 2008, 2009; Holle et al., 2008; Straube et al., 2009), and that areas outside of the traditional language network can be involved in language understanding. An example of the latter is activation of the motor cortex when participants read action-related language (e.g., "He kicks the ball”; Hauk et al., 2004; Tettamanti et al., 2005; Aziz-Zadeh et al., 2006; Willems and Hagoort, 2007; Willems et al., 2010b,c).

However, we feel that incorporating mentalizing abilities into an extended language network is not a helpful conceptualization. We showed evidence for a separation of mentalizing abilities and linguistic abilities in the human brain, such as in the case of patients who have lost the capacity for language, but are still able to communicate. Moreover, lexico-semantic processing can be distinguished from communicative message generation in the healthy human brain. The separation of linguistic and communicative abilities therefore seems a more fruitful characterization rather than calling both "language," and allows for some forms of communication that are not linguistic. Although it is clear that there is not a single, monolithic neural network only involved in language (see e.g., Willems and Hagoort, 2007), it seems reasonable to use the term "language network" for areas involved in the traditional semantic, syntactic and phonological processing triangle as a shorthand in scientific literature as well as in clinical practice. However, it must be realized that other parts of the brain are crucially involved in everyday language production and comprehension.

\section{A COUNTER-ARGUMENT FROM DEVELOPMENT}

There is a sizeable literature which argues for the opposite conclusion to the one that we have reached, namely that language and mentalizing/communicative abilities are causally related and that the capacity to mentalize about others' beliefs, intentions and desires crucially depends upon language abilities. An important source of evidence for this position is the observation that performance on false belief tasks correlates with several aspects of language development (Milligan et al., 2007; see Pyers, 2006 for discussion).
From this association, it has been taken that the capacity to understand intentions of others (that is, to possess a ToM) is crucially dependent upon certain aspects of language being in place. A full exposition of this literature is beyond the scope of our paper, but it should be noted that this conclusion relies on equating performance on false belief tasks with intention recognition or mentalizing abilities. This relationship has been criticized because false belief tasks tax multiple cognitive systems, and plausibly involve other factors than "just" mentalizing, such as working memory load (e.g., Bloom and German, 2000). Furthermore, false belief tasks may only tap into a subset of ToM capabilities and indeed, research with preverbal infants seems to suggest that equating false belief understanding with mentalizing abilities is not well justified. That is, despite the absence of syntactic structures and lexical forms that have been claimed to be necessary for the representation of false beliefs, there is evidence that preverbal infants show the capacity to understand another person's intentions (Behne et al., 2005; Liszkowski, 2006; Liszkowski et al., 2008; cf. Aureli et al., 2009), and to attribute false beliefs to another individual (Onishi and Baillargeon, 2005; Baillargeon et al., 2010).

Some have argued that, although the abilities of infants show that intention recognition can precede language development, it is not until relatively late in preschool years (around 4 years of age) that children develop "the real thing" for ToM, namely false belief understanding (Pyers, 2006). This argument is reminiscent of the quote with which we started our contribution. Searle argued that communication without language is perhaps possible, but that this is just a marginal phenomenon, as one cannot communicate about abstract and difficult concepts such as mononucleosis without language (see Introduction and Searle, 1969). In the case of false belief understanding and language development, this argument breaks down when we again recognize that false belief tasks include components other than intention recognition alone. Moreover, the compelling evidence for intention recognition abilities in preverbal infants cannot be marginalized by referring to the inability of children under 4 years of age to pass a false belief task.

On top of the evidence from pre-verbal infants, we described findings from severely aphasic patients who, despite their severe limitation in language ability, are able to pass false belief tests. This casts further doubt upon the relationship between language and mentalizing abilities in the sense that even on standard measures of mentalizing, performance can be maintained without a fully functioning language system. It is possible that the role of language in mentalizing may be restricted to configuring the capacity for ToM in early childhood, and thus if language is impaired in later life as in acquired aphasia, mentalizing ability is not lost with the loss of language. However, the convergence of evidence from infancy and adults with aphasia strengthens the case as to the considerable autonomy between these two cognitive capacities.

\section{CONCLUSION}

In summary, we reviewed evidence from neuroimaging in healthy participants as well as results from neuropsychological populations which show that the generation of a communicative message is best thought of as a capacity which is distinct from core linguistic processes. Hence the perspective from neuroscience compellingly argues for loosening the presumed causal ties between communicative 
abilities and language, and between mentalizing abilities and language (e.g., Sperber and Wilson, 1995; Tomasello et al., 2005; Levinson, 2006; Tomasello, 2008; Airenti, 2010; Bara, 2010).

A similar conclusion can be reached from research in infants. The claimed interdependence of mentalizing and language seems to be mainly due to the heavy reliance in experimental studies on false belief tasks, which are theoretically well motivated (Wimmer and Perner, 1983), but should perhaps not be taken as the only proxy for testing mentalizing abilities (Bloom and German, 2000). It will be a challenge for future research to develop new paradigms to test communicative abilities which suffer less from confounding factors (see de Ruiter et al., 2010 for an example).

Given the paucity of available data, there are many directions for future research. First, future work on healthy adults should be aimed at investigating how the two neural systems interact since

\section{REFERENCES}

Airenti, G. (2010). Is a naturalistic theory of communication possible? Cogn. Syst. Res. 11, 165-180.

Amodio, D. M., and Frith, C. D. (2006). Meeting of minds: the medial frontal cortex and social cognition. Nat. Rev. Neurosci. 7, 268-277.

Apperly, I. A., Samson, D., Carroll, N., Hussain, S., and Humphreys, G. (2006). Intact first- and second-order false belief reasoning in a patient with severely impaired grammar. Soc. Neurosci. 1, 334-348.

Aureli, T., Perucchini, P., and Genco, M. (2009). Children's understanding of communicative intentions in the middle of the second year of life. Cogn. Dev. 24, 1-12.

Aziz-Zadeh,L., Wilson,S.M., Rizzolatti, G., and Iacoboni, M. (2006). Congruent embodied representations for visually presented actions and linguistic phrases describing actions. Curr. Biol. 16, 1818-1823.

Baillargeon, R., Scott, R. M., and He, Z. (2010). False-belief understanding in infants. Trends Cogn. Sci. 14, 110-118.

Bara, B. G. (2010). Cognitive Pragmatics. Cambridge, MA: MIT Press.

Bara, B. G., Cutica, I., and Tirassa, M. (2001). Neuropragmatics: extralinguistic communication after closed head injury. Brain Lang. 77, 72-94.

Baron-Cohen, S., Leslie, A. M., and Frith, U. (1985). Does the autistic child have a "theory of mind"? Cognition 21,37-46.

Behne, T., Carpenter, M., and Tomasello, M. (2005). One-year-olds comprehend the communicative intentions behind gestures in a hiding game. $D e v$. Sci. 8, 492-499.

Bird, C. M., Castelli, F., Malik, O., Frith, U., and Husain, M. (2004). The impact of extensive medial frontal lobe damage on 'Theory of Mind' and cognition. Brain 127(Pt 4), 914-928.
Bloom, P., and German, T. P. (2000). Two reasons to abandon the false belief task as a test of theory of mind. Cognition 77, B25-B31.

Bookheimer, S. (2002). Functional MRI of language: new approaches to understanding the cortical organization of semantic processing. Annu. Rev. Neurosci. 25, 151-188.

Carruthers, P. (2002). The cognitive functions of language. Behav. Brain Sci. 25, 657-726.

Ciaramidaro, A., Adenzato, M., Enrici, I., Erk, S., Pia, L., Bara, B. G., and Walter, H. (2007). The intentional network: how the brain reads varieties of intentions. Neuropsychologia 45, 3105-3113.

de Ruiter, J. P., Noordzij, M. L., NewmanNorlund, S., Hagoort, P., and Toni, I. (2007). "On the origin of intentions," in Sensorimotor Foundations of Higher Cognition, eds Y. Rossetti, P. Haggard and M. Kawato (Oxford: Oxford University Press), 593-610.

de Ruiter, J. P., Noordzij, M. L., NewmanNorlund, S., Newman-Norlund, R., Hagoort, P., Levinson, S. C., and Toni, I. (2010). Exploring the cognitive infrastructure of communication. Interact. Stud. 11, 51-77.

Ferstl, E. C., Neumann, J., Bogler, C., and von Cramon, D. Y. (2008). The extended language network: a metaanalysis of neuroimaging studies on text comprehension. Hum. Brain Mapp. 29, 581-593.

Frith, C. D., and Frith, U. (2006). The neural basis of mentalizing. Neuron $50,531-534$

Goodwin, C. (1995). Co-constructing meaning in conversations with an aphasic man. Res. Lang. Soc. Interact. $28,233-260$

Goodwin, C. (2006). "Human sociality as mutual orientation in a rich interactive environment: multimodal utterances and pointing in aphasia," in Roots of Human Sociality, eds N. J. Enfield

they are obviously closely related. Second, research in healthy as well as in neuropsychological populations should be used to gain more adequate tools for assessment and improvement of communicative abilities in those with severe language difficulties. Finally, neuroimaging work in developing populations should investigate the intricate interplay between neural language development and development of mentalizing abilities.

\section{ACKNOWLEDGMENTS}

Supported by the Netherlands Organisation for Scientific Research (NWO Rubicon 446-08-008) and the Niels Stensen Foundation. Publication costs of this article were paid through a grant from the Netherlands Organisation for Scientific Research Open Access initiative. We are most grateful to the constructive criticism and recommendations from two reviewers.

and S. C. Levinson (New York: Berg), $97-125$.

Hagoort, P. (2005). On Broca, brain, and binding: a new framework. Trends Cogn. Sci. 9, 416-423.

Happe, F., Brownell, H., and Winner, E. (1999). Acquired 'theory of mind' impairments following stroke. Cognition 70, 211-240.

Hauk, O., Johnsrude, I., and Pulvermuller, F. (2004). Somatotopic representation of action words in human motor and premotor cortex. Neuron 41, 301-307.

Holle, H., Gunter, T. C., Ruschemeyer, S. A., Hennenlotter, A., and Iacoboni, M. (2008). Neural correlates of the processing of co-speech gestures. Neuroimage 39, 2010-2024.

Indefrey, P., and Levelt, W. J. (2004). The spatial and temporal signatures of word production components. Cognition 92, 101-144.

Kampe, K. K., Frith, C. D., and Frith, U. (2003). "Hey John”: signals conveying communicative intention toward the self activate brain regions associated with "mentalizing," regardless of modality. J. Neurosci. 23 , 5258-5263.

Levinson, S. C. (1983). Pragmatics. Cambridge,UK: Cambridge University Press.

Levinson, S. C. (2006). "On the human interactional engine," in Roots of Human Sociality, eds N. J. Enfield and S. C. Levinson (New York: Berg), 39-69.

Liszkowski, U. (2006). "Infant pointing at 12 months: communicative goals, motives, and social-cognitive abilities," in Roots of Human Sociality, eds N. J. Enfield and S. C. Levinson (New York: NY: Berg), 153-178.

Liszkowski, U., Carpenter, M., and Tomasello, M. (2008). Twelvemonth-olds communicate helpfully and appropriately for knowledgeable and ignorant partners. Cognition 108 732-739.
McCarthy, R., and Warrington, E. K. (1985). Category specificity in an agrammatic patient: the relative impairment of verb retrieval and comprehension. Neuropsychologia 23, 709-727.

Milligan, K., Astington, J. W., and Dack, L. A. (2007). Language and theory of mind: meta-analysis of the relation between language ability and falsebelief understanding. Child Dev. 78, 622-646.

Newman-Norlund, S. E., Noordzij, M. L., Newman-Norlund, R. D., Volman, I. A., Ruiter, J. P., Hagoort, P., and Toni, I. (2009). Recipient design in tacit communication. Cognition 111, 46-54.

Newton, A.M., and de Villiers, J.G. (2007). Thinking while talking: adults fail nonverbal false-belief reasoning. Psychol. Sci. 18, 574-579.

Noordzij, M. L., Newman-Norlund, S. E., de Ruiter, J.P., Hagoort, P., Levinson, S. C., and Toni, I. (2009). Brain mechanisms underlying human communication. Front. Hum. Neurosci. 3:14. doi: 10.3389/neuro.09.014.2009.

Onishi, K. H., and Baillargeon, R. (2005). Do 15-month-old infants understand false beliefs? Science 308, 255-258.

Pyers, J.E. (2006). "Constructing the social mind: language and false-belief understanding," in Roots of Human Sociality, eds N. J. Enfield and S. C. Levinson (New York: Berg), 207-228.

Pyers, J. E., and Senghas, A. (2009). Language promotes false-belief understanding: evidence from learners of a new sign language. Psychol. Sci. 20, 805-812.

Sassa, Y., Sugiura, M., Jeong, H., Horie, K., Sato, S., and Kawashima, R. (2007). Cortical mechanism of communicative speech production. Neuroimage 37, 985-992.

Schippers, M. B., Gazzola, V., Goebel, R., and Keysers, C. (2009). Playing charades in the fMRI: are mirror and/or mentalizing areas involved in gestural 
communication? PLoS ONE 4, e6801. doi: 10.1371/journal.pone.0006801.

Searle, J. R. (1969). Speech Acts; An Essay in the Philosophy of Language. Cambridge, UK: Cambridge University Press.

Siegal, M., and Varley, R. (2002). Neural systems involved in "theory of mind". Nat. Rev. Neurosci. 3, 463-471.

Sperber, D., and Wilson, D. (1995). Relevance; Communication and Cognition, 2nd Edn. Oxford, UK: Basil Blackwell.

Straube, B., Green,A., Weis, S., Chatterjee,A., and Kircher, T. (2009). Memory effects of speech and gesture binding: cortical and hippocampal activation in relation to subsequent memory performance. $J$. Cogn. Neurosci. 21, 821-836.

Tettamanti, M., Buccino, G., Saccuman, M. C., Gallese, V., Danna, M., Scifo, P., Fazio, F., Rizzolatti, G., Cappa, S. F., and Perani, D. (2005). Listening to action-related sentences activates fronto-parietal motor circuits. J. Cogn. Neurosci. 17, 273-281.

Tirassa, M. (1999). Communicative competence and the architecture of the mind/brain. Brain Lang. 68, 419-441.

Tomasello, M. (2008). Origins of Human Communication. Cambridge, MA: MIT press.
Tomasello, M., Carpenter, M., Call, J., Behne, T., and Moll, H. (2005). Understanding and sharing intentions: the origins of cultural cognition. Behav. Brain Sci. 28, 675-691; discussion 691-735.

Tylen, K., Wallentin, M., and Roepstorff, A. (2009). Say it with flowers! An fMRI study of object mediated communication. Brain Lang. 108, 159-166.

Varley, R., and Siegal, M. (2000). Evidence for cognition without grammar from causal reasoning and 'theory of mind' in an agrammatic aphasic patient. Curr. Biol. 10, 723-726.

Varley, R., Siegal, M., and Want, S. C. (2001). Severe impairment in grammar does not preclude theory of mind. Neurocase 7, 489-493.

Vigneau, M., Beaucousin, V., Herve, P. Y., Duffau, H., Crivello, F., Houde, O., Mazoyer, B., and Tzourio-Mazoyer, N. (2006). Meta-analyzing left hemisphere language areas: phonology, semantics, and sentence processing. Neuroimage 30, 1414-1432.

Walter, H., Adenzato, M., Ciaramidaro, A., Enrici, I., Pia, L., and Bara, B. G. (2004). Understanding intentions in social interaction: the role of the anterior paracingulate cortex. J. Cogn. Neurosci. 16, 1854-1863.
Willems, R. M., de Boer, M., de Ruiter, J. P., Noordzij, M. L., Hagoort, P., and Toni, I. (2010a).A cerebral dissociation between linguistic and communicative abilities in humans. Psychol. Sci. 21, 8-14.

Willems, R.M.,Hagoort, P., and Casasanto D. (2010b). Body-specific representations of action verbs: neural evidence from right- and left-handers. Psychol. Sci. 21, 67-74.

Willems, R. M., Toni, I., Hagoort, P., and Casasanto, D. (2010c). Neural dissociations between action verb understanding and motor imagery. J. Cogn. Neurosci. 22, 2387-2400.

Willems, R. M., and Hagoort, P. (2007) Neural evidence for the interplay between language, gesture, and action: a review. Brain Lang. 101, 278-289.

Willems, R. M., Özyürek, A., and Hagoort, P. (2007). When language meets action: the neural integration of gesture and speech. Cereb. Cortex 17, 2322-2333.

Willems, R. M.,Özyürek, A., and Hagoort P. (2008). Seeing and hearing meaning: ERP and fMRI evidence of word versus picture integration into a sentence context. J. Cogn. Neurosci. 20, 1235-1249.

Willems, R. M., Özyürek, A., and Hagoort P. (2009). Differential roles for left inferior frontal and superior temporal cortex in multimodal integration of action and language. Neuroimage 47, 1992-2004.

Wimmer, H., and Perner, J. (1983). Beliefs about beliefs: representation and constraining function of wrong beliefs in young children's understanding of deception. Cognition 13, 103-128.

Conflict of Interest Statement: The authors declare that the research was conducted in the absence of any commercial or financial relationships that could be construed as a potential conflict of interest.

Received:26April 2010; paperpending published: 04 May 2010; accepted: 04 October 2010; published online: 25 October 2010.

Citation: Willems RM and Varley R (2010) Neural insights into the relation between language and communication. Front. Hum. Neurosci. 4:203. doi: 10.3389/ fnhum.2010.00203

Copyright (C) 2010 Willems and Varley. This is an open-access article subject to an exclusive license agreement between the authors and the Frontiers Research Foundation, which permits unrestricted use, distribution, and reproduction in any medium, provided the original authors and source are credited. 